\title{
BMJ Open Change in paternity, risk of placental abruption and confounding by birth interval: a population-based prospective cohort study in Norway, 1967-2009
}

\author{
Cande V Ananth, ${ }^{1,2}$ Rolv Skjaerven, ${ }^{3,4}$ Kari Klunssoyr ${ }^{3,4}$
}

To cite: Ananth CV, Skjaerven R, Klunssoyr K. Change in paternity, risk of placental abruption and confounding by birth interval: a population-based prospective cohort study in Norway, 1967-2009. BMJ Open 2015;5:e007023. doi:10.1136/bmjopen-2014007023

- Prepublication history for this paper is available online. To view these files please visit the journal online (http://dx.doi.org/10.1136/ bmjopen-2014-007023).

Received 27 October 2014 Revised 6 January 2015 Accepted 13 January 2015

CrossMark

For numbered affiliations see end of article.

Correspondence to Dr Rolv Skaerven; rolv.skjarven@smis.uib.no

\section{ABSTRACT}

Objectives: We examined abruption risk in relation to change in paternity, and evaluated if birth interval confounds this association.

Setting: Population-based study of singleton births in Norway between 1967 and 2009.

Participants: Women who had their first two $(n=747566)$ singleton births in the Norwegian Medical Birth Registry. The associations between partner change between pregnancies and birth interval were examined in relation to abruption in a series of logistic regression models.

Primary outcome measures: Risk, as well as unadjusted and adjusted $\mathrm{OR}$ of placental abruption in relation to change in paternity and interval between births.

Results: Among women without abruption in their first pregnancy, the risks of abruption in the second pregnancy were 4.7 and 6.5 per 1000 in women who had the same and different partners, respectively (OR=1.39, 95\% $\mathrm{Cl} 1.26$ to 1.53 ). After adjustments for confounders including birth interval and smoking, partner change was not associated with abruption $(\mathrm{OR}=1.01,95 \% \mathrm{Cl} 0.79$ to 1.32 ). Among women with abruption in the first pregnancy, the association between partner change and abruption in the second pregnancy was 0.98 ( $95 \% \mathrm{Cl} 0.75$ to 1.28$)$. Interval $<1$ year was associated with increased abruption risk in the second pregnancy among women with the same as well as different partners, but interval over 4 years was only associated with increased risk among women with the same partner. No such patterns were seen for recurrent abruption.

Conclusions: We find no evidence that a change in partner is associated with increased abruption risk. Theories supporting an immune maladaptation hypothesis afforded by change in paternity are not supported insofar as abruption is concerned.

\section{INTRODUCTION}

Placental abruption, the premature separation of the implanted placenta prior to delivery of the fetus, complicates 4-12 per 1000 pregnancies. ${ }^{1-4}$ Abruption is a devastating
Strengths and limitations of this study

- Large, population-based prospective cohort study with almost 750000 women who delivered their first two singleton births in Norway.

- This study sheds light regarding the association between change in paternity and abruption risk, and the role of interval between births.

- The prevalence rate of placental abruption is low in this cohort.

- In about $1.7 \%$ of pregnancies we were unable to assign the correct paternity.

- The possibility of the findings affected by residual confounding is likely.

obstetrical complication, with such pregnancies ending roughly 2-4 weeks earlier and newborns weighing 400-600 g less in comparison with otherwise uncomplicated pregnancies. ${ }^{5}$ This early delivery as a consequence of abruption, in turn, is associated with disproportionately increased risks of perinatal mortality, ${ }^{6}$ as well as cerebral palsy ${ }^{7}$ and developmental delays during childhood. ${ }^{8}$ Women who suffer an abruption are at increased risks of premature death from cardiovascular and cerebrovascular complications later in life. ${ }^{9} 10$

Since placental abruption is a condition that involves the placenta, a postulation that its aetiology may likely bear both a maternal and fetal contribution, at least partly inherited from the father, appears reasonable. Evidence for this line of reasoning can also be found in studies that have shown that abruption has an immunological underpinning. ${ }^{11}$ The argument to support an immune-mediated process to abruption is that the maternal immune system adapts to paternal antigens through imprinting in pregnancies with extended periods of sexual cohabitation. When women change partners between pregnancies, they are exposed to a new set of paternal antigens likely contributing to increased abruption risk. 
However, studies of partner change and adverse perinatal end points often fail to incorporate adjustments for one of the strongest known confounders-birth interval. ${ }^{12}$ A change in partner between pregnancies inevitably alters the interval between births. In comparison to women who remain with the same partners, those who change partners between pregnancies are different as regards sociodemographic and behavioural factors, and lifestyle characteristics. These women, in general, are older, less educated and more likely to smoke in comparison to those who do not change partners. ${ }^{13} 14$

Even within the group that changes partners, women with very short birth intervals may be a distinctly different set from those with relatively longer intervals. The higher risk of abruption in women with short intervals may suggest nutritional deficiencies, including those that involve the folate metabolism pathway, and a uterine environment not optimally primed to carry the next pregnancy to a successful delivery. Folate deficiency, especially 3 months before pregnancy and during the first trimester, ${ }^{15}$ and genes that regulate folate metabolism, ${ }^{16-19}$ are associated with increased abruption risk.

However, a change in partner invariably prolongs the time to the next pregnancy and leads to longer birth intervals. Although the pathways through which extended intervals may confer increased abruption risk are unclear, we suspect that the longer interval may reflect increased subfertility in these couples, especially among those with the same partner. Furthermore, it is likely that with uterine ageing (attributed to previous pregnancies and extended interval between pregnancies), the physiological capacity to reproduce may decline.

Indeed, if the risk of abruption increases with a change in partner between pregnancies, then the immune adaptation pathway may provide important clues. Nevertheless, we hypothesise that the increased abruption risk in relation to change in paternity may simply be a manifestation of strong confounding attributed to interval between births. We test this hypothesis in a large population-based prospective cohort study of births in Norway.

\section{METHODS}

This study is based on a prospective cohort, with data derived from the Medical Birth Registry of Norway (MBRN), comprised of approximately 2.2 million births between 1967 and 2009. Notification to the MBRN is compulsory, and data on births is completed using a standardised notification form. ${ }^{20}$ The notification form was unchanged from 1967 to 1998, and data were mostly notified as free text specifications to items such as 'Maternal health before pregnancy,' 'Maternal health during pregnancy' and 'Complications in relation to birth'. In 1999, a revised notification form was introduced, which contained a few additional items such as maternal smoking habits and ultrasound-estimated due dates, and check boxes were introduced in addition to free text. Electronic birth notification, where predefined variables replaced the check boxes, has been used for an increasing proportion of births since 2006, but except for the inclusion of maternal weight and height, the content has been unchanged since 1998 .

In Norway, every individual is assigned a unique national identification number at birth, which is registered in the Central Person Registry. This identification number enables linking successive pregnancies to the same woman. The MBRN is routinely linked with the Central Person Registry, and through this linkage, identification numbers of all fathers are collected as well as all dates of deaths. We also used the identification numbers to link the MBRN with the National Education Database, Statistics Norway, where educational level of all individuals in Norway has been registered since 1970. Any education completed in Norway is registered when the individual is 16 years of age, and this information is updated yearly. Missing information in the education database is mainly found in immigrants who have recently come to the country and who have not completed any education in Norway.

\section{Definition of placental abruption}

Placental abruption was defined as the premature separation of an implanted placenta prior to delivery of the fetus. During 1967-1998, data on abruption was notified to the registry in free text as a specification to the item: 'Complications in relation to birth'. Since 1999, abruption was notified using a check box (or a predefined value) or in free text. Data in free text were coded at the MBRN using the International Classification of Diseases (ICD) 8th revision, for births delivered before 1999, and the ICD 10th revision for births from 1999 onwards.

\section{Change in paternity}

Change in paternity was defined as women who changed their partner between births. Cohabiting and married couples were treated equally. The MBRN ascertains the national identification numbers of the woman's husband or cohabiting partner through routine linkage with the Central Person Registry. For live births, who get their national identification number at birth and thus can be identified in the Central Person Registry, information on the father is collected automatically through the linkage. For stillbirths, which do not get a national identification number, the fathers' identification numbers are collected on the basis of information on the birth notification form regarding father's name and birth date. This information is used in a manual search in the Central Person Registry to find the full identification number.

During the study period, of the 747566 women who had their first and second singleton births, 89.1\% ( $\mathrm{n}=666401)$ had the same partner for both pregnancies, $9.2 \%(\mathrm{n}=68663)$ changed partners between pregnancies and for $12502(1.7 \%)$ women we were unable to assign paternity status. 


\section{Definition of birth interval}

Birth interval was calculated as the time between consecutive birth dates (calculated in days and subsequently converted to years). In other words, a birth interval of 3 years corresponds to a period of 3 years but less than 4 completed years. Given the $100 \%$ completeness in using dates of birth, rather than approximate dates of conception, we based our calculation on birth intervals. Since the focus was on short and long birth intervals, the effect of using birth date rather than the date of conception is expected to be minimal.

\section{Statistical analysis}

We examined the association of partner change and the risk of abruption and reported OR with 95\% CI derived from logistic regression models. These preliminary analyses were followed by a series of sequential adjustments for confounding factors. First, we adjusted the association between partner change and abruption for interval between births (categorised as $<1,1-1.9,2-2.9,3-3.9$, $4-4.9,5-5.9,6-7.9,8-9.9,10-12.9$ and $\geq 13$ years). This was followed by further adjustment for maternal age $(<20$, 20-24, 25-29, 30-34, 35-39 and $\geq 40$ years), maternal education $(<12,12-13$ and $\geq 14$ years of schooling), marital status (married/cohabitating, single and others) and period of birth $(1967-1971,1972-1976, \ldots, 2002-2009)$ to account for temporal changes in the prevalence of abruption. All analyses were performed separately for women with and without abruption in their first pregnancy.

Data on maternal smoking, an important risk factor for abruption, ${ }^{321}$ are recorded in the MBRN only since 1999. In a subanalysis restricted to births between 1999 and 2009 ( $\mathrm{n}=191953$ women), we evaluated the abruption risk by partner change, and birth interval after adjusting for maternal smoking and the aforementioned confounders.

\section{RESULTS}

The distribution of maternal characteristics in relation to the risk of placental abruption in the first pregnancy is shown in table 1 . The incidence of abruption showed a reversed 'U'-shaped pattern with a peak around 19871991. The risk increased with advancing maternal age and was higher among single women, smokers (since 1999) and those with a diagnosis of chronic hypertension, preeclampsia and pregestational diabetes.

\section{Risk of placental abruption following change in paternity}

Among women with and without abruption in the first pregnancy, the risks of abruption in the second pregnancy were 38.7 and 5.0 per 1000 births, respectively (table 2). Among women with no abruption in the first pregnancy, the risks of abruption were 4.7 and 6.5 per 1000 in the second pregnancy in women with the same and different partners, respectively. Among women with abruption in the first pregnancy, the risks of recurrent abruption among women with the same and different partners, were 38.4 and 36.9 per 1000, respectively.
Interestingly, the risk of abruption in the second pregnancy was higher in women with unknown paternity status.

Among women with no previous abruption, following adjustment for birth interval, a change in partner was associated with a $17 \%$ (OR $1.17,95 \%$ CI 1.04 to 1.32 ) increased risk of abruption in the second pregnancy (table 3). Further adjustments for other confounding factors slightly attenuated this risk. However, in a subset of this cohort restricted to women who had their first two births between 1999 and 2009, when these associations were additionally adjusted for maternal smoking, the association of increased abruption risk following a change in partner completely disappeared. When the association between partner change and abruption risk was examined among women with abruption in the first pregnancy, we found that partner change was not associated with abruption recurrence.

\section{Influence of birth interval on abruption risk}

The risk of abruption in relation to interval between births shows a reversed 'J'-shaped pattern (figure 1). Among women with no previous abruption and with the same partner, the risk of abruption in the second pregnancy was 14.2 per 1000 for an interval $<1$ year and the risk sharply declined with increasing interval, reaching a nadir at 3-4 years (4 per 1000) and began to rise thereafter. Among women who changed partners, the risk of abruption in the second pregnancy was 25.6 per 1000 for an interval <1 year, and declined sharply and remained virtually flat with increasing intervals.

We detected an interaction of marginal significance between birth interval and change in paternity on abruption risk $(p=0.045)$. Therefore, we examined the effects of birth interval on abruption risk separately among women with the same and different partners between the first two pregnancies (figure 2). Among women who did not change partners between pregnancies and no abruption in the first pregnancy, compared to interval $2-3$ years, the odds of abruption in the second pregnancy with an interval $<1$ year were 3.4 (95\% CI 2.7 to 4.3$)$. As the pregnancy interval increased to 4 or more years, the odds of abruption also increased. Among women who changed partners between pregnancies with no abruption in the first pregnancy, compared to women with intervals of 2-3 years, the odds of abruption in women with interval $<1$ year were 4.8 (95\% CI 1.1 to 20.5); longer intervals were not associated with increased odds of abruption. These patterns of associations were not seen for recurrent abruptions (data not shown).

\section{Sensitivity analysis}

A variety of factors can shape a couple's decision to undergo a pregnancy. Importantly, couples with a perinatal loss in one pregnancy continue to have another pregnancy more often and more quickly to achieve a desired family size than couples without such losses-a phenomenon called 'selective fertility'. ${ }^{22}{ }^{23}$ We examined if bias due to selective fertility may have affected 
Table 1 Distribution of maternal characteristics in relation to placental abruption in the first singleton pregnancy: Norway, 1967-2009

\begin{tabular}{|c|c|c|c|c|}
\hline \multirow{2}{*}{$\begin{array}{l}\text { Maternal characteristics } \\
\text { in the first pregnancy }\end{array}$} & \multirow{2}{*}{$\begin{array}{l}\text { Total births } \\
(\mathrm{n}=988027)\end{array}$} & \multicolumn{3}{|c|}{ Placental abruption in the first pregnancy } \\
\hline & & Number $(n=5327)$ & Risk per 1000 births & OR $(95 \% \mathrm{Cl})$ \\
\hline \multicolumn{5}{|l|}{ Period of delivery } \\
\hline $1967-1971$ & 128344 & 637 & 5.0 & $1.3(1.2$ to 1.4$)$ \\
\hline 1972-1976 & 122941 & 634 & 5.2 & $1.3(1.2$ to 1.5$)$ \\
\hline 1977-1981 & 105412 & 602 & 5.7 & $1.5(1.3$ to 1.7$)$ \\
\hline 1982-1986 & 106715 & 720 & 6.7 & 1.8 (1.6 to 2.0$)$ \\
\hline $1987-1991$ & 123474 & 869 & 7.0 & $1.8(1.7$ to 2.0$)$ \\
\hline 1992-1996 & 119084 & 685 & 5.8 & $1.5(1.3$ to 1.6$)$ \\
\hline 1997-2001 & 109060 & 513 & 4.7 & $1.2(1.1$ to 1.4$)$ \\
\hline 2002-2009 & 172997 & 668 & 3.9 & 1.0 (Referent) \\
\hline \multicolumn{5}{|l|}{ Maternal age (years) } \\
\hline$<20$ & 127127 & 714 & 5.6 & 1.1 (1.1 to 1.3$)$ \\
\hline $20-24$ & 383943 & 2039 & 5.3 & $1.1(1.0$ to 1.2$)$ \\
\hline $25-29$ & 314625 & 1547 & 4.9 & 1.0 (Referent) \\
\hline $30-34$ & 123999 & 748 & 6.0 & $1.2(1,1$ to 1.3$)$ \\
\hline $35-39$ & 33054 & 234 & 7.3 & $1.4(1.3$ to 1.7$)$ \\
\hline$\geq 40$ & 5278 & 46 & 8.1 & 1.8 (1.3 to 2.4$)$ \\
\hline \multicolumn{5}{|l|}{ Education (years) } \\
\hline$<12$ & 387224 & 2408 & 6.2 & $1.3(1.3$ to 1.4$)$ \\
\hline 12 & 243918 & 1261 & 5.2 & 1.1 (1.0 to 1.2$)$ \\
\hline$\geq 13$ & 332478 & 1548 & 4.7 & 1.0 (Referent) \\
\hline \multicolumn{5}{|l|}{ Marital status } \\
\hline Married/cohabitating & 820580 & 4193 & 5.0 & 1.0 (Referent) \\
\hline Single & 159172 & 1080 & 6.8 & $1.3(1.2$ to 1.4$)$ \\
\hline Others & 8275 & 55 & 6.6 & $1.3(1.0$ to 1.7$)$ \\
\hline \multicolumn{5}{|l|}{ Chronic hypertension } \\
\hline Absent & 985482 & 5300 & 5.4 & 1.0 (Referent) \\
\hline Present & 2545 & 28 & 11.0 & $2.1(1.4$ to 3.0$)$ \\
\hline \multicolumn{5}{|l|}{ Preeclampsia } \\
\hline Absent & 945461 & 4770 & 5.0 & 1.0 (Referent) \\
\hline Present & 42566 & 558 & 13.1 & 2.6 (2.4 to 2.9 ) \\
\hline \multicolumn{5}{|l|}{ Pregestational diabetes } \\
\hline Absent & 984309 & 5296 & 5.4 & 1.0 (Referent) \\
\hline Present & 3519 & 31 & 8.8 & $1.6(1.2$ to 2.3$)$ \\
\hline \multicolumn{5}{|l|}{ Gestational diabetes } \\
\hline Absent & 984752 & 5311 & 5.4 & 1.0 (Referent) \\
\hline Present & 3275 & 17 & 5.2 & $1.0(0.6$ to 1.6$)$ \\
\hline \multicolumn{5}{|l|}{ Smoking history (1999-) } \\
\hline Non-smoker & 163038 & 588 & 3.6 & 1.0 (Referent) \\
\hline Daily smoker & 2498 & 18 & 7.2 & $2.0(1.3$ to 3.2$)$ \\
\hline Occasional smoker & 19470 & 101 & 5.2 & 1.5 (1.2 to 1.8$)$ \\
\hline Unknown & 51370 & 2294 & 4.5 & $1.2(1.1$ to 1.4$)$ \\
\hline
\end{tabular}

our findings. After excluding women with a perinatal loss (stillbirth or deaths within the first month), the associations between change in paternity between the first two births and abruption risk remained unchanged. These results were also similar in another analysis after excluding women with a diagnosis of preeclampsia in the first pregnancy, as well as women who had spontaneous abortions in the first trimester.

\section{DISCUSSION}

In this large population-based cohort of singleton births in Norway, following adjustments for smoking and other confounders, women who change partners between their first two pregnancies are not at increased risk of developing abruption in the second pregnancy. We also show that regardless of partner change, birth interval $<1$ year is strongly associated with increased risk of abruption, but this association was confined to women with no abruption in their first pregnancy. Intervals longer than 4 years are also associated with increased risk, although this association was only seen among women who did not change partners.

The mother and the father each play important roles in the implantation, development, maturation and subsequent detachment of the placenta. While placental 
Table 2 Risk of placental abruption among women with the same and different partners between the first and second pregnancies: Norway, 1967-2009

\begin{tabular}{|c|c|c|c|c|c|}
\hline & \multirow{2}{*}{$\begin{array}{l}\text { Interval between } \\
\text { births (median years) }\end{array}$} & \multicolumn{2}{|l|}{ Total pregnancies } & \multicolumn{2}{|c|}{ Abruption in second pregnancy } \\
\hline & & Number of births & Per cent & Number of cases & Risk per 1000 \\
\hline \multicolumn{6}{|c|}{ No abruption in 1st pregnancy } \\
\hline Overall & 3.0 & 747566 & 100.0 & 3723 & 5.0 \\
\hline Same partner & 2.8 & 666401 & 89.1 & 3110 & 4.7 \\
\hline Different partners & 6.8 & 68663 & 9.2 & 444 & 6.5 \\
\hline Unknown status & 4.0 & 12502 & 1.7 & 169 & 13.5 \\
\hline \multicolumn{6}{|c|}{ Abruption in 1st pregnancy } \\
\hline Overall & 3.5 & 4061 & 100.0 & 157 & 38.7 \\
\hline Same partner & 3.0 & 3356 & 82.6 & 129 & 38.4 \\
\hline Different partners & 7.1 & 406 & 10.0 & 15 & 36.9 \\
\hline Unknown status & 3.9 & 299 & 7.4 & 13 & 43.5 \\
\hline
\end{tabular}

implantation is under the control of maternal genes, the growth of membranes surrounding the embryo is primarily influenced by paternal genes. ${ }^{24}{ }^{25}$ Since abruption is a condition that involves the placenta, a study of maternal and paternal contributions is important to understand the causes of the inadequate placental attachment and premature placental detachment-both of which can lead to the syndrome of placental abruption. ${ }^{26} 27$

\section{Limitations of the data}

Despite the sheer size of the cohort, a few important limitations of the study exist. First, the prevalence of

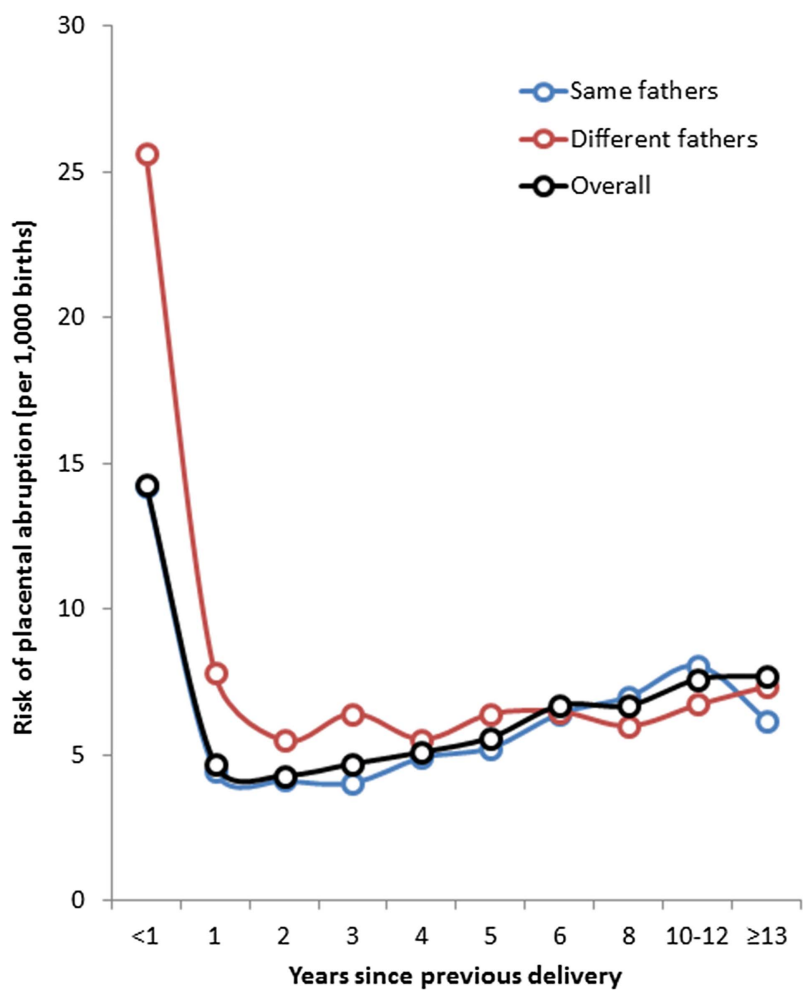

Figure 1 Risk of placental abruption (per 1000 births) in the second pregnancy among women with the same and different partners: Norway, 1967-2009. abruption in this Norwegian cohort (5 per 1000) is somewhat lower than that reported in the $\mathrm{USA}^{28}$ and Canada $^{29}$ (7-13 per 1000), but consistent with rates reported in Sweden ${ }^{12}$ and Finland. ${ }^{30}$ Although variability in the criteria for ascertainment of abruption may account for such differences in prevalence rates, we suspect that these differences may be due to differences in maternal sociodemographic characteristics and clinical profiles. Second, an abruption diagnosis was extracted from free-text data between 1967 and 1998, and using a check box, in addition to free text since 1999 in the Medical Birth Registry. However, temporal trends of registered abruption prevalence in the MBRN do not show any particular change in 1999 (http:// mfr-nesstar.uib.no/mfr/). Third, since ultrasound (for diagnosing abruption) was unavailable during the earlier periods of the study, the diagnosis of abruption may have been subject to more misclassification in the earlier rather than later periods in the study. Fourth, we were unable to assess paternity status in $1.7 \%$ of births in Norway. Although this proportion is small, the prevalence rate of abruption in this missing paternity group was about twofold higher in comparison to births for which paternity status was recorded.

The associations we report of partner change, interval between births and abruption risk may have been affected by residual confounding. Specifically, these covariates include maternal prepregnancy body mass index, subfertility and smoking and drug use during pregnancy. Although data on these confounders were unavailable in the entire cohort, we were able to adjust for smoking in an analysis restricted to women who gave birth since 1999.

\section{Strengths of the study}

The large cohort of women with successive pregnancies in Norway spanning over four decades (1967-2009) afforded an opportunity to study a rare obstetrical complication of abruption in relation to change in paternity and interval between births. Since virtually all births at $\geq 16$ weeks undergo mandatory reporting to the MBRN, any study within the registry affords generalisability of 
Table 3 Risk of placental abruption in second pregnancy in relation to partner change between the first and second pregnancies: Norway, 1967-2009

\begin{tabular}{|c|c|c|c|c|}
\hline & \multicolumn{4}{|c|}{ Adjusted OR $(95 \% \mathrm{Cl})$ for placental abruption in second pregnancy } \\
\hline & Unadjusted & $\begin{array}{l}\text { Adjusted for } \\
\text { birth interval }\end{array}$ & $\begin{array}{l}\text { Complete } \\
\text { adjustment }\end{array}$ & $\begin{array}{l}\text { Complete adjustment, } \\
\text { 1999-2009† }\end{array}$ \\
\hline \multicolumn{5}{|c|}{ No abruption in 1st pregnancy } \\
\hline Same father & 1.00 (Referent) & 1.00 (Referent) & 1.00 (Referent) & 1.00 (Referent) \\
\hline Different father & 1.39 (1.26 to 1.53$)$ & $1.17(1.04$ to 1.32$)$ & $1.13(1.00$ to 1.28$)$ & 1.01 (0.79 to 1.32$)$ \\
\hline \multicolumn{5}{|c|}{ Abruption in 1st pregnancy } \\
\hline Same father & 1.00 (Referent) & 1.00 (Referent) & 1.00 (Referent) & 1.00 (Referent) \\
\hline Different father & $0.96(0.56$ to 1.66$)$ & 1.35 (0.71 to 2.57$)$ & $1.27(0.66$ to 2.44$)$ & $0.98(0.75$ to 1.28$)$ \\
\hline
\end{tabular}

findings. Importantly, abruption cases may be subject to some degree of misclassification, but the impact of such misclassification on our findings remains unknown. Finally, given that virtually all births in Norway were analysed, the possibility of our findings being affected by selection bias remains low.

\section{Change in paternity and abruption risk}

Why might a change in partner be associated with increased abruption risk? Studies that have reported such findings have hypothesised that a cause for such an association may have to do with a general failure of the mother to adapt to a new set of paternal antigens in conjunction with a change in partner. ${ }^{31}$ In a study comparing women diagnosed with preterm abruption $(n=15)$ with those who had uncontrolled labour (unresponsive to tocolytic administration) and also delivered at preterm gestational ages $(\mathrm{n}=33)$, Steinborn $e t a \hat{l}^{2}$ reported that the proportion of women producing antipaternal human leucocyte antigen antibodies was increased in the preterm abruption (47\%) compared to the preterm labour (14\%) group. They concluded that an increased humoral immune response of the mother against the fetus may be decisively involved in the pathogenesis of abruption. ${ }^{32}$

This immune theory, if true, should also support an observation that in women who changed partners and with very short birth interval, there must be a higher risk of abruption. We see this to be true in our data (figure 2), but the risk of abruption is equally high in women who did not change partners and had a short interval. This suggests that the immune maladaptation theory plays virtually no role in the pathophysiology of abruption and that birth interval (and other factors) may have a stronger role in shaping abruption risk-a finding that is also supported in studies of preeclampsia. ${ }^{33}$

\section{Birth interval and abruption risk}

Among women with no abruption in the first pregnancy, we observed an increased risk of abruption in the second pregnancy among women with short $(<1$ year $)$ birth intervals. Maternal nutritional reserves get depleted with pregnancy, and women with short interval between pregnancies do not have adequate time to restore their nutritional reserves. Folates play an important role during pregnancy, especially during the early stages of conception where they help in accelerated cell division and
Figure 2 Adjusted OR $(95 \% \mathrm{Cl})$ of placental abruption in the second pregnancy in relation to interval between the first and second births among women with no placental abruption in the first pregnancy: Norway, 1967-2009. Left panel corresponds to women with the same partner and the right panel corresponds to women who changed partners between the two pregnancies.
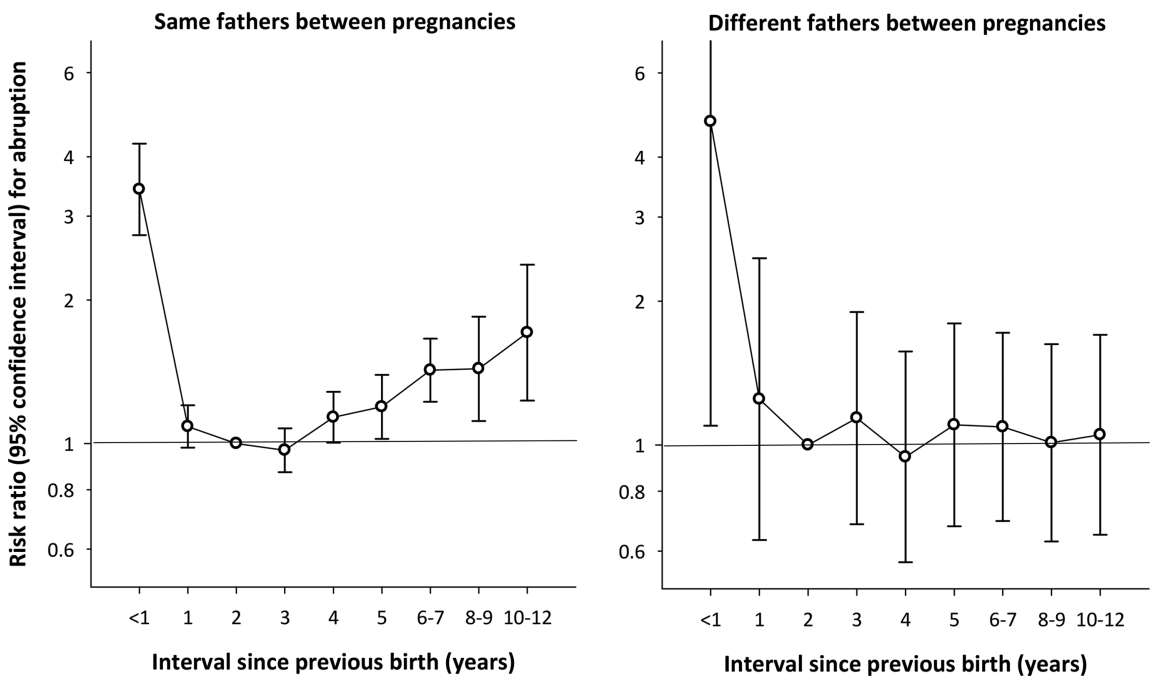
DNA synthesis. ${ }^{34}$ Low plasma folate levels, in contrast, are associated with increased abruption risk, ${ }^{17} 35$ with results from a meta-analysis noting an OR of 25.9 (95\% CI 0.9 to 736.3) for abruption in relation to folate deficiency. ${ }^{19}$ A large population-based study from Norway $^{15}$ also reported reduced abruption risk (OR 0.7, 95\% CI 0.6 to 0.8 ) among women who took folic acid and multivitamin supplementation during pregnancy.

Despite the associations of increased risk of adverse perinatal outcomes ${ }^{26} 27$ including abruption seen in our study in relation to long birth intervals, ${ }^{28} 2932-37$ no convincing hypotheses have been advanced to explain such an association, nor is one obvious to us. The fact that this increased risk in second pregnancies was only found in women with same partners further complicates the issue. We suspect that subfertility may play a role. However, we could not find any increased risk of abruption associated with in vitro fertilisation (data not shown). A pregnancy primes the physiological capacity for women to reproduce by providing increased capillary support and uteroplacental blood flow and other adaptations of the reproductive system. Zhu et $a l^{36}$ speculated that as the interval between births gets longer, the physiological capacity of women to reproduce diminishes with ageing of the uterine environment.

Factors other than nutritional deficiency may also help explain the association of long intervals and increased risk of abruption. These include maternal stress and anxiety associated with the new pregnancy, and presence of adverse outcomes in the previous pregnancy, especially ischaemic placental disorders such as preeclampsia and fetal growth restriction, all of which lead to early delivery. ${ }^{38}{ }^{39}$ Poor socioeconomic conditions and untoward behavioural and lifestyle factors that may frequently accompany women with very short and very long birth intervals, could also partly explain the associations.

\section{CONCLUSIONS}

Following adjustments for interval between births and other known confounders, a change in paternity between pregnancies is not associated with abruption. In contrast, among women with no abruption in their first pregnancy, those with birth intervals less than a year are at over threefold increased risk for abruption, regardless of partner change. Adequate nutritional counselling, coupled with evidence of reduced risk of abruption in women who consume folate and multivitamin supplementation before and during pregnancy, may help in reducing the burden of placental abruption and associated complications.

\footnotetext{
Author affiliations

${ }^{1}$ Department of Obstetrics and Gynecology, College of Physicians and Surgeons, Columbia University, New York, New York, USA

${ }^{2}$ Department of Epidemiology, Mailman School of Public Health, Columbia University, New York, New York, USA

${ }^{3}$ Department of Global Public Health and Primary Care, University of Bergen, Bergen, Norway
}

${ }^{4}$ Medical Birth Registry of Norway, Norwegian Institute of Public Health, Bergen, Norway

Contributors CVA and RS were involved in study concept and design. CVA was responsible for drafting of the manuscript. All authors were responsible for analysis and interpretation of the data, and critical revision of the manuscript for important intellectual content. RS had full access to all of the data in the study and takes responsibility for the integrity of the data and the accuracy of the data analysis.

Funding This research received no specific grant from any funding agency in the public, commercial or not-for-profit sectors.

Competing interests None.

Provenance and peer review Not commissioned; externally peer reviewed.

Data sharing statement No additional data are available.

Open Access This is an Open Access article distributed in accordance with the Creative Commons Attribution Non Commercial (CC BY-NC 4.0) license, which permits others to distribute, remix, adapt, build upon this work noncommercially, and license their derivative works on different terms, provided the original work is properly cited and the use is non-commercial. See: http:// creativecommons.org/licenses/by-nc/4.0/

\section{REFERENCES}

1. Cnattingius S, Mills JL, Yuen J, et al. The paradoxical effect of smoking in preeclamptic pregnancies: smoking reduces the incidence but increases the rates of perinatal mortality, abruptio placentae, and intrauterine growth restriction. Am J Obstet Gynecol 1997;177:156-61.

2. Elsasser DA, Ananth CV, Prasad V, et al. Diagnosis of placental abruption: relationship between clinical and histopathological findings. Eur J Obstet Gynecol Reprod Biol 2010;148:125-30.

3. Kramer MS, Usher RH, Pollack R, et al. Etiologic determinants of abruptio placentae. Obstet Gynecol 1997;89:221-6.

4. Rasmussen S, Irgens LM, Bergsjo P, et al. The occurrence of placental abruption in Norway 1967-1991. Acta Obstet Gynecol Scand 1996;75:222-8.

5. Ananth CV, Berkowitz GS, Savitz DA, et al. Placental abruption and adverse perinatal outcomes. JAMA 1999;282:1646-51.

6. Ananth CV, VanderWeele TJ. Placental abruption and perinatal mortality with preterm delivery as a mediator: disentangling direct and indirect effects. Am J Epidemiol 2011;174:99-108.

7. Thorngren-Jerneck K, Herbst A. Perinatal factors associated with cerebral palsy in children born in Sweden. Obstet Gynecol 2006;108:1499-505.

8. Spinillo A, Fazzi E, Stronati M, et al. Severity of abruptio placentae and neurodevelopmental outcome in low birth weight infants. Early Hum Dev 1993;35:45-54.

9. Ray JG, Vermeulen MJ, Schull MJ, et al. Cardiovascular health after maternal placental syndromes (CHAMPS): population-based retrospective cohort study. Lancet 2005;366:1797-803.

10. Pariente G, Shoham-Vardi I, Kessous R, et al. Placental abruption as a significant risk factor for long-term cardiovascular mortality in a follow-up period of more than a decade. Paediatr Perinat Epidemiol 2014;28:32-8

11. Christiansen OB, Steffensen R, Nielsen HS. The impact of anti-HY responses on outcome in current and subsequent pregnancies of patients with recurrent pregnancy losses. J Reprod Immunol 2010;85:9-14.

12. Basso $\mathrm{O}$, Christensen $\mathrm{K}$, Olsen J. Higher risk of pre-eclampsia after change of partner. An effect of longer interpregnancy intervals? Epidemiology 2001;12:624-9.

13. Fu H, Goldman N. The association between health-related behaviours and the risk of divorce in the USA. J Biosoc Sci 2000;32:63-88.

14. Vatten LJ, Skjaerven R. Effects on pregnancy outcome of changing partner between first two births: prospective population study. BMJ 2003;327:1138.

15. Nilsen RM, Vollset SE, Rasmussen SA, et al. Folic acid and multivitamin supplement use and risk of placental abruption: a population-based registry study. Am J Epidemiol 2008;167:867-74.

16. Ananth CV, Elsasser DA, Kinzler WL, et al. Polymorphisms in methionine synthase reductase and betaine-homocysteine S-methyltransferase genes: risk of placental abruption. Mol Genet Metab 2007;91:104-10. 
17. Ananth CV, Peltier MR, Moore DF, et al. Reduced folate carrier 80A-->G polymorphism, plasma folate, and risk of placental abruption. Hum Genet 2008;124:137-45.

18. Zdoukopoulos N, Zintzaras E. Genetic risk factors for placental abruption: a HuGE review and meta-analysis. Epidemiology 2008;19:309-23.

19. Ray JG, Laskin CA. Folic acid and homocyst(e)ine metabolic defects and the risk of placental abruption, pre-eclampsia and spontaneous pregnancy loss: a systematic review. Placenta 1999;20:519-29.

20. Irgens LM. The Medical Birth Registry of Norway. Epidemiological research and surveillance throughout 30 years. Acta Obstet Gynecol Scand 2000;79:435-9.

21. Ananth CV, Cnattingius S. Influence of maternal smoking on placental abruption in successive pregnancies: a population-based prospective cohort study in Sweden. Am J Epidemiol 2007;166:289-95.

22. Wilcox AJ, Gladen BC. Spontaneous abortion: the role of heterogeneous risk and selective fertility. Early Hum Dev 1982;7:165-78.

23. Skjaerven R, Wilcox AJ, Lie RT, et al. Selective fertility and the distortion of perinatal mortality. Am J Epidemiol 1988;128:1352-63.

24. Tilghman SM. The sins of the fathers and mothers: genomic imprinting in mammalian development. Cell 1999;96:185-93.

25. Bartolomei MS, Tilghman SM. Genomic imprinting in mammals. Annu Rev Genet 1997:31:493-525.

26. Ananth CV, Getahun D, Peltier MR, et al. Placental abruption in term and preterm gestations: evidence for heterogeneity in clinical pathways. Obstet Gynecol 2006;107:785-92.

27. Ananth CV, Kinzler WL. Placental abruption: Clinical features and diagnosis. Secondary placental abruption: clinical features and diagnosis 2014. http://www.uptodate.com/contents/placentalabruption-clinical-features-and-diagnosis
28. Ananth CV, Savitz DA, Williams MA. Placental abruption and its association with hypertension and prolonged rupture of membranes: a methodologic review and meta-analysis. Obstet Gynecol 1996:88:309-18.

29. McDonald SD, Vermeulen MJ, Ray JG. Risk of fetal death associated with maternal drug dependence and placental abruption: a population-based study. J Obstet Gynaecol Can 2007;29:556-9.

30. Tikkanen M, Nuutila M, Hiilesmaa V, et al. Clinical presentation and risk factors of placental abruption. Acta Obstet Gynecol Scand 2006;85:700-5.

31. Sibai BM. Immunologic aspects of preeclampsia. Clin Obstet Gynecol 1991;34:27-34.

32. Steinborn A, Rebmann V, Scharf A, et al. Placental abruption is associated with decreased maternal plasma levels of soluble HLA-G. J Clin Immunol 2003;23:307-14.

33. Skjaerven R, Wilcox AJ, Lie RT. The interval between pregnancies and the risk of preeclampsia. N Engl J Med 2002;346:33-8.

34. van Eijsden M, Smits LJ, van der Wal MF, et al. Association between short interpregnancy intervals and term birth weight: the role of folate depletion. Am J Clin Nutr 2008;88:147-53.

35. Ananth CV, Peltier MR, De Marco C, et al. Associations between 2 polymorphisms in the methylenetetrahydrofolate reductase gene and placental abruption. Am J Obstet Gynecol 2007;197:385.e1-7.

36. Zhu BP, Rolfs RT, Nangle BE, et al. Effect of the interval between pregnancies on perinatal outcomes. N Engl J Med 1999;340:589-94.

37. Conde-Agudelo A, Rosas-Bermudez A, Kafury-Goeta AC. Birth spacing and risk of adverse perinatal outcomes: a meta-analysis. JAMA 2006;295:1809-23.

38. Rasmussen S, Irgens LM, Dalaker K. A history of placental dysfunction and risk of placental abruption. Paediatr Perinat Epidemiol 1999;13:9-21.

39. Ananth CV, Peltier MR, Chavez MR, et al. Recurrence of ischemic placental disease. Obstet Gynecol 2007;110:128-33. 